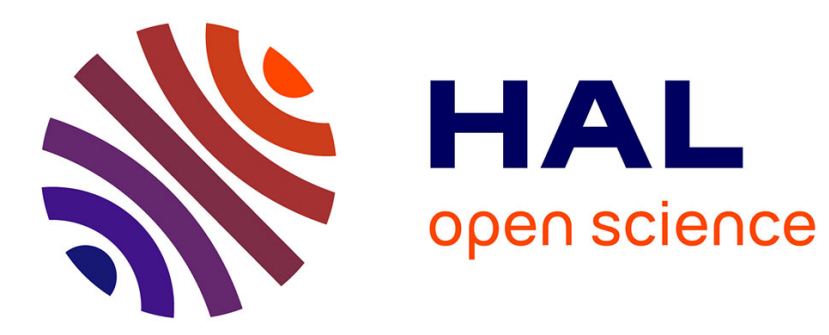

\title{
Assimilation of Hydrocarbons and Lipids by Means of Biofilm Formation
}

Pierre Sivadon, Regis. Grimaud

\section{To cite this version:}

Pierre Sivadon, Regis. Grimaud. Assimilation of Hydrocarbons and Lipids by Means of Biofilm Formation. Cellular Ecophysiology of Microbe, 2017. hal-01676300

\section{HAL Id: hal-01676300 https://hal.science/hal-01676300}

Submitted on 11 Jan 2018

HAL is a multi-disciplinary open access archive for the deposit and dissemination of scientific research documents, whether they are published or not. The documents may come from teaching and research institutions in France or abroad, or from public or private research centers.
L'archive ouverte pluridisciplinaire HAL, est destinée au dépôt et à la diffusion de documents scientifiques de niveau recherche, publiés ou non, émanant des établissements d'enseignement et de recherche français ou étrangers, des laboratoires publics ou privés. 


\section{Assimilation of hydrocarbons and lipids by means of biofilm formation}

2 Pierre Sivadon and Régis Grimaud

3 CNRS/ UNIV PAU \& PAYS ADOUR, INSTITUT DES SCIENCES ANALYTIQUES ET

4 DE PHYSICO-CHIMIE POUR L'ENVIRONNEMENT ET LES MATERIAUX - MIRA,

5 UMR5254, 64000, PAU, FRANCE

6

ABSTRACT: Hydrophobic organic compounds (HOCs) that are used as substrates by bacteria, encompass a great variety of molecules, including contaminants such as hydrocarbons and natural components of the organic matter such as lipids. It is now well known that many bacterial strains use HOCs as carbon and energy sources for growth and form biofilms at the HOCs-water interface that are referred to as oleolytic biofilms. The formation of these biofilms appears to be a strategy to overcome the low accessibility of nearly water-insoluble substrates and is therefore a critical process in the biodegradation of hydrocarbons and lipids. Because oleolytic biofilms develop on a nutritive interface serving as both substratum and substrate, they represent an original facet of biofilm biology.

\section{Introduction}

Early studies on hydrocarbon biodegradation led to the observation that hydrocarbondegrading bacteria had high affinity for oil droplets. Phase contrast and electron microscopy examination of Acinetobacter sp. growing on $n$-hexadecane revealed hydrocarbon spheres densely covered with bacterial cells and suggested close contact between the cells and oil droplets (Kennedy et al., 1975). Since then, similar observations have been reiterated with various alkane-degrading strains, such as Rhodococcus sp. Q15 (Whyte et al., 1999), Acinetobacter venetianus RAG-1 (Baldi et al., 1999), Oleiphilus messinensis (Golyshin et al., 2002), Pseudomonas UP-2 (Zilber Kirschner et al., 1980) and Marinobacter hydrocarbonoclasticus SP17 (figure 1) (Klein et al., 2008). Bacterial attachment to polycyclic aromatic hydrocarbons (PAHs) has also been described for Pseudomonas spp. (Eriksson et 
al., 2002; Mulder et al., 1998), Sphingomonas sp. CHY-1 (Willison, 2004) and

Mycobacterium frederiksbergense LB501T (Bastiaens et al., 2000). In biphasic culture medium containing a poorly water-soluble substrate and the aqueous phase, substrate-bound cells often coexist with cells floating freely in the aqueous phase. Although the presence of hydrocarbon-bound cells at the interface assumes interfacial growth, demonstration of actual substrate degradation and growth of the attached cells has been provided in only a few cases (Efroymson and Alexander, 1991; Wick et al., 2003; Zilber Kirschner et al., 1980). The sessile mode of life and the multilayered structure of cell populations growing at the interface between hydrophobic organic compounds (HOCs) and water are reminiscent of biofilms. During the last two decades, biofilms have been the subject of extensive investigations. Most of our knowledge about the molecular biology of biofilms has been derived from model strains such as Pseudomonas aeruginosa and Escherichia coli. This research has revealed that biofilms are much more than the simple accretion of cells attached to an interface. Biofilms are heterogeneous, highly organized structures possessing an architecture that is essential to their functioning. Biofilm growth follows a stepwise pattern involving differentiation and collective behavior of cells (Stewart and Franklin, 2008; Webb et al., 2003). Molecular studies of oleolytic biofilms growing at hydrophobic interfaces have not yet gone far enough to conclude whether they share all the characteristics of extensively studied model biofilms. However, properties characteristic of the biofilm lifestyle have been identified. CSLM (Confocal Scanning Laser Microscopy) observation of a biofilm community developing at polychlorinated biphenyl-water interface provided evidence of a stepwise development pattern of the biofilm (Macedo et al., 2005). Transcriptomic and proteomic studies indicated that cells growing at the alkane-water interface experienced a profound reshaping of their gene expression profile (Mounier et al., 2014; Vaysse et al., 2009; Vaysse et al., 2010). Extracellular polymeric substances (EPS), polysaccharides, DNA and proteins 
have been detected during growth at the alkane-water interface, indicating production of an extracellular matrix, which is a typical trait of biofilms (Ennouri et al., 2017; Whyte et al., 1999).

In this chapter, biofilms on HOCs refer to multilayered, matrix-embedded bacteria or bacterial communities growing at the HOCs-water interface and using these compounds as a substrate. In such biofilms, the energy and the carbon, which fuel bacterial growth, are provided by the degradation of the substrate, which thus constitutes a nutritive interface serving as both substrate and substratum.

\section{Multispecies biofilms on hydrophobic interface}

During enrichment procedures on hydrocarbons, microbiologists have very often observed multispecies biofilms developing at the hydrocarbon-water interface. For example, Deppe $e t$ al. (2005) have observed by phase contrast microscopy oil droplets covered by a biofilm during isolation of a consortium enriched on crude oil from Arctic sea ice and seawater from Spitzbergen. Unfortunately, such observations received little attention and in consequence they are not always mentioned in the literature and are rarely fully documented, making it difficult to measure the occurrence of these biofilms among bacterial species. Stach et al. (2002) carried out a study devoted to the diversity of biofilm communities developing on PAHs. Biofilms developing on naphthalene- and phenanthrene-coated flow cells were isolated and their diversity compared with planktonic cultures enriched on the same hydrocarbons. The biofilm system showed a three times higher diversity of cultivable bacteria as compared to the enrichment culture. Molecular approaches revealed that the biofilm community contained a greater diversity of active species and of PAH-degradation genes than the planktonic enrichment community. The diversity of active species found in the biofilm closely matched the diversity found in the PAH-contaminated soil used as inoculum. This study 
demonstrates that biofilm cultures represent a means to obtain PAH-degrading communities closely related to environmental situations suggesting that biofilm formation on hydrocarbons is a likely lifestyle in natural ecosystems. The existence of biofilms at oil-water interfaces in natural environments has been reported during the Deepwater Horizon oil spill where bacterial flocs were observed in the oil plume. Synchrotron radiation-based Fourier-transform infrared-spectra of these flocs indicated that their formation occurred on the surface of oil droplets and revealed the presence of oil-degradation products, polysaccharides and proteins (Baelum et al., 2012; Hazen et al., 2010).

\section{Cell adhesion to hydrophobic compounds}

In order to either develop a biofilm or to grow as single cell layers at the interface, bacteria must first approach and then adhere to the interface. Bacteria can reach surfaces by passive diffusion, random swimming, or taxis that is a directed motility in response to gradients of chemical and physical stimuli. Chemotaxis has been observed in response to single ring aromatic hydrocarbons, naphthalene, and hexadecane. Regrettably, no experiment designed to determine whether this behavior led to biofilm formation at the interface between water and hydrocarbons has been conducted (Lanfranconi et al., 2003; Pandey and Jain, 2002). To date, random mobility like swimming has never been shown to play a role in adhesion to HOCs. Once cells have reached the interface, the initial adhesion step is a purely physicochemical process described by the traditional and extended DLVO theories of colloidal stability, which describes contact of cells to surfaces as the result of van der Waals interactions, Lewis acidbase interactions, and electrostatic interactions (Hermansson, 1999). The intensity of these interactions and hence the effectiveness of the binding depend on the cell surface properties (hydrophobicity, charge, roughness, etc...) as well as interface properties. This means that only bacteria exhibiting the proper surface properties will adhere on hydrophobic surfaces (for 
103 a detailed review of bacterial adhesion to hydrocarbon, see Abbasnezhad et al., 2011). In

104 contrast to adhesion to biotic surfaces or insoluble polysaccharides like chitin or cellulose, no

105 specific adhesins or receptors recognizing hydrocarbons or lipids have been identified so far.

106 In many cases, adhered cells exhibit surface properties that are different from their soluble

107 substrate-grown counterparts. These alterations of the cell surface are thought to strengthen

108 adhesion after the initial interaction with the interface. For example, anthracene-grown cells

109 of Mycobacterium sp. LB501T are more hydrophobic and more negatively charged than

110 glucose-grown cells (Wick et al., 2002). Changes in cell surface can be achieved by

111 modification, production, or removal of their surface molecules. In Gram-positive bacteria,

112 the presence and the chain length of mycolic acids are correlated with hydrophobicity and

113 adherence (Bendinger et al., 1993). Lipopolysaccharides are important determinants of cell

114 surface properties in Gram-negative bacteria. Their chain length variation or their removal

115 from the cell surface has been shown to be important for interacting with hydrocarbons (Al-

116 Tahhan et al., 2000). Capsular polysaccharides are another class of surface molecules playing

117 a role in adhesion to hydrophobic compounds (Baldi et al., 1999).

118 Adhesion to hydrophobic surfaces is also mediated by extracellular appendages such as

119 fimbriae and pili. The importance of fimbriae in adherence to $n$-hexadecane was demonstrated

120 by the isolation of a non-adherent mutant of Acinetobacter calcoaceticus RAG-1, which was

121 devoid of fimbriae and defective for growth on hydrocarbons. The reappearance of fimbriae

122 in adherent revertants was a strong argument in favor of the involvement of fimbriae in

123 adhesion to hexadecane (Rosenberg et al., 1982). The strains Acinetobacter haemolyticus AR-

12446 and Acinetobacter sp. Tol 5 produce pili at their cell surfaces when grown on $n$ -

125 hexadecane or triglycerides, respectively. Although the function of these organelles has not

126 been elucidated it was presumed that they play a role during the adhesion to the hydrophobic

127 substrate (Bihari et al., 2007; Katsutoshi et al., 2011). Changes in surface properties of cells 
grown on hydrophobic substrates and inhibition of adhesion in the presence of soluble

129 substrates indicate that the process of adhesion is regulated and that cells are able to respond

130 to contact with hydrophobic interfaces.

\section{Regulation and determinism of biofilm formation at the HOC-water interfaces}

133 In biofilms growing on an inert substratum, all nutrients are supplied through the aqueous

134 phase. In biofilms on HOCs, the situation is very different. These biofilms develop in a

135 biphasic medium where the electron donor is provided by the non-aqueous phase and the

136 electron acceptor (e.g., oxygen) is available from the aqueous phase. It results in a geometry

137 in which one side of the biofilm is in close association with the electron source, while the

138 other contacts the source of the electron acceptor. Thus, cells within the biofilm experience

139 two opposite gradients of acceptor and donor of electron generated by their simultaneous

140 diffusion and consumption. These microscale chemical gradients presumably contribute to the

141 physiological heterogeneity in the biofilm and exert a control on its development. The

142 experiment carried out by Joannis-Cassan et al. (2005) demonstrated that biofilm growth on

143 hydrocarbons can be limited either by carbon or by oxygen depletion. The authors studied

144 biofilm growth in a liquid-liquid system consisting of an emulsion obtained by stirring

145 dodecane in mineral medium. Biofilm growth occurred at the surface of a dodecane droplet.

146 During growth, the droplet diameter was reduced from $200 \mu \mathrm{m}$ to $160 \mu \mathrm{m}$. Biofilm growth

147 ceased when it reached a maximum thickness of about $80 \mu \mathrm{m}$. A series of experiments

148 demonstrated that inhibition of growth was caused by the diffusion limitation of both

149 dodecane and oxygen within the biofilm but not by others factors such as nutrient exhaustion

150 or product inhibition (Joannis-Cassan et al., 2005).

151 Although adhesion to hydrocarbons does not seem to depend on the recognition of molecular

152 structures, many HOC-degrading bacteria show a preference or specificity to the surface of 
153 metabolizable hydrocarbons or lipids for biofilm formation (Johnsen and Karlson, 2004;

154 Klein et al., 2008; Rodrigues et al., 2005). The substrate/substratum specificity of biofilm on 155 hydrocarbons is certainly one remarkable feature that distinguishes them from other biofilms.

156 Biofilm formation tends to occur preferentially on less-soluble substrates and seems to be

157 regulated in function of substrate availability. Screening for biofilm formation capacity by

158 isolated PAHs-degrading strains showed that the majority of the tested strains formed biofilm

159 in microtiter wells coated with PAH crystals. For strains capable of growing on different

160 PAHs, it was observed that the percentage of adhering cells decreased with the solubility of

161 the PAHs, indicating that aqueous solubility of the substrate exerts a regulation on biofilm

162 development (Johnsen and Karlson, 2004). Pseudomonas putida ATCC 17514 exhibits

163 different growth patterns depending on the PAH properties on which it is feeding. CSLM

164 observation of a gfp-labeled derivative of this strain showed that growth on phenanthrene

165 occurred by forming a biofilm at the crystal surface, while on fluorene, which is more soluble

166 than phenanthrene, $P$. putida grew randomly between the crystals feeding on dissolved PAH

167 (Rodrigues et al., 2005). Insoluble substrate preference for biofilm formation has also been

168 observed in M. hydrocarbonoclasticus SP17. This bacterium forms biofilms on a variety of

169 HOCs, including $n$-alkanes, wax esters, and triglycerides, but is unable to form biofilm (in

170 presence of acetate as substrate) on non-metabolizable alkanes (branched alkanes and $n$ -

171 alkanes with more than 28 carbon atoms) and forms only weak biofilms on polystyrene with

17210 times less biomass than on paraffin (Ennouri et al., 2017; Klein et al., 2008). The

173 preference for insoluble substrates suggests that bacteria forming biofilms on HOCs are able

174 to detect and recognize nutritive interfaces. It is reasonable to anticipate that control of

175 biofilm formation by substrate/substratum is exerted through a signal transduction pathway

176 and genetic regulatory mechanisms. Indeed, induction of genes at an interface was

177 demonstrated for the pra gene encoding the PA protein, an alkane inducible extracellular 
178 protein exhibiting an emulsifying activity involved in hexadecane assimilation, and the $r h l R$

179 gene coding for the transcriptional activator of rhamnolipids biosynthesis. Studies with liquid

180 cultures on hexadecane of $P$. aeruginosa harboring a pra::gfp or rhlR::gfp fusion revealed

181 specific transcriptional activity at the $n$-hexadecane-water interface (Holden et al., 2002).

183 Biofilm formation as an adaptive response to optimize acquisition of insoluble HOCs

184 The first intuitive indications that biofilms could favor access to poorly soluble HOCs came 185 from the observations that biofilm formation occurs in function of substrate solubility since it

186 was shown that the more insoluble the substrate is, the more growth occurs at the water-HOC 187 interface. Moreover, it was observed that several strains growing at the interface between 188 nearly insoluble hydrocarbons and water do not release emulsifier or surface-active 189 compounds into the bulk medium (Bouchez et al., 1997; Bouchez-Naïtali et al., 1999; 190 Bouchez-Naïtali et al., 2001; Klein et al., 2008; Wick et al., 2002). In these cases, cells do not 191 access the substrate by surfactant-mediated transfer, during which cells contact emulsified, 192 solubilized or pseudo solubilized hydrocarbons. Access to the insoluble substrate rather 193 occurs by direct contact of the cells or extracellular structures with the hydrocarbon-water 194 interface. Rosenberg demonstrated the importance of adhesion to hydrocarbons in the growth 195 of Acinetobacter calcoaceticus RAG-1 on hexadecane in absence of any emulsifier 196 (Rosenberg and Rosenberg, 1981). Thus, biofilm formation and adhesion to hydrocarbons 197 would promote growth on hydrocarbons by facilitating interfacial access. The strongest 198 evidence of an increase in access to HOCs by adhesion or biofilm formation arose from

199 kinetic studies showing that growth at the interface occurs faster than the mass transfer rate of 200 HOCs in the absence of bacteria would suggest (Bouchez-Naïtali et al., 2001; Calvillo and 201 Alexander, 1996; Harms and Zehnder, 1995; Wick et al., 2002). 
Mechanisms employed in biofilms for accessing HOCs are still poorly understood. On the one

203 hand, it is not difficult to imagine that biofilms offer a way to optimize the effect of known 204 mechanisms of acquisition of poorly soluble hydrophobic substrates. Surfactant production 205 within a biofilm would limit its dilution in the bulk phase, facilitating the formation of 206 micelles by keeping the concentration of the surfactant close to the critical micelle 207 concentration (CMC). Biofilms also offer the advantage of holding the cell population in the 208 vicinity of the HOC-water interface thus stimulating the mass transfer of HOCs by shortening 209 the diffusive pathway (Wick et al., 2002). On the other hand, biofilm lifestyle might offer 210 possibilities of biofilm-specific mechanisms for HOCs accession. Biofilms are typically 211 characterized by dense cell clusters embedded in extracellular polymeric substances. The 212 formation of such structures involves profound changes in cell physiology and behavior 213 requiring regulation of the expression of hundreds of genes. Such changes in cellular 214 physiology has been indeed revealed by transcriptomic and proteomic studies on biofilms of M. hydrocarbonoclasticus growing at HOCs-water interfaces (Mounier et al., 2014; Vaysse et 216 al., 2009; Vaysse et al., 2010). The transition from the planktonic to the biofilm mode on 217 HOCs entails change in the expression level of more than one thousand genes . Although 218 most of these genes are of unknown function some of them are involved in cellular processes 219 like lipid, alkanesand central metabolisms, chemotaxis, motility, transport and protein 220 secretion. In view of such a reshaping of cellular functions and structural organization, the 221 existence of biofilm-specific mechanisms for HOCs accession is conceivable.

222 For instance, biofilms can improve the assimilation of HOCs through their extracellular 223 matrix. Many functions currently attributed to the biofilm matrix, e.g. adhesion to surfaces 224 and retention of enzymes and metabolites, can have implications in the assimilation of HOCs 225 (Flemming and Wingender, 2010). The retention properties of the matrix could maintain exo226 products in the vicinity of cells and prevent their loss in the bulk medium. The action of 
biosurfactants, which has been demonstrated to improve assimilation of hydrocarbons in some 228 cases (Perfumo et al., 2010), could be greatly increased within a matrix by enabling their accumulation up to the CMC and thus allow micellar transport of hydrocarbons (Guha and Jaffé, 1996). In addition, EPS of the biofilm matrix may act as sorbents or emulsifiers that could stimulate the mass transfer rate of HOCs (Harms et al., 2010). Various strains of

Acinetobacter sp. produce extracellular complexes of polysaccharides or lipo-polysaccharides

233 and proteins called bio-emulsans that have the capacity to emulsify and increase the solubility 234 of hydrocarbons (Barkay et al., 1999; for reviews see Ron and Rosenberg, 2002; Ron and 235 Rosenberg, 2010). Although the emulsifying activities were not localized within a biofilm 236 matrix, these results indicate that biopolymers could increase mass transfer rates of 237 hydrocarbons and hence stimulate their biodegradation. Direct interactions between EPS and 238 hydrocarbons have been evidenced in A. venetianus VE-C cells growing on diesel fuel where nano-droplets incorporated in an extracellular matrix containing glyco-conjugates were 240 observed (Baldi et al., 1999; Baldi et al., 2003). Similarly, oil droplets were completely 241 covered with cells and EPS in a culture of Rhodococcus sp. strain Q15 on diesel fuel (Whyte 242 et al., 1999). In both cases, EPS mediated the adhesion of cells to hydrocarbons and are 243 thought to participate in the uptake of hydrocarbons, although the mechanisms involved remain unknown. Biofilm EPS can also serve as an adsorbent to store HOCs and allow their 245 subsequent utilization by the biofilm community (Wolfaardt et al., 1995).

246 Biofilm matrices comprise extracellular proteins with various functions such as hydrolytic 247 enzymes or adhesion (Flemming and Wingender, 2010). The involvement of extracellular 248 proteins in alkane utilization was first evidenced in A. calcoaceticus ADP1 as it was shown 249 that a Type 2 Secretion System (T2SS) mutant showed reduced growth on alkanes (Parche et 250 al., 1997). The OmpA-like AlnA protein of A. radioresistens KA53 and the PA protein from 251 P. aeruginosa PG201 and S7B1 are two extracellular proteins that have been shown to play a 
252 role in alkane utilization in planktonic culture (Hardegger et al., 1994; Kenichi et al., 1977).

253 These two proteins exhibit emulsifying properties that have been claimed to be the basis of 254 their function in alkane assimilation although no clear cause-to-effect relationship has been 255 established. During biofilm development on alkanes or triglycerides $M$. 256 hydrocarbonoclasticus SP17 uses cytoplasmic proteins released by cell lysis and proteins 257 secreted through the T2SS to form a proteinaceous matrix (Ennouri et al., 2017). It was 258 hypothesized that the surface activity of proteins could be exploited in oleolytic biofilm matrices to form a conditioning film at the HOC-water interface that could promote cell adhesion and colonization. Matrix proteins could also participate in the mass transfer of HOCs to the biofilm cells by forming micelles or acting as mobile sorbents.

\section{Research Needs}

264 The most exciting aspect of biofilms on HOCs is certainly to identify the features that distinguish them from other biofilms, that is to say, their substrate/substratum specificity and their capacity to overcome the low accessibility of a hydrophobic substrate. These two 267 properties make biofilm formation a very efficient adaptive strategy to assimilate HOCs, 268 which can provide a serious advantage in environments where carbon sources are scarce. The 269 processes by which biofilms stimulate interfacial accession to nearly insoluble substrates remain to be elucidated. Substrate specificity of biofilm formation for HOCs surfaces

271 presumably involves surface sensing and signal transduction pathways, which have not been 272 revealed yet. Biofilm development during the assimilation of HOCs most likely requires 273 coordination of fundamental processes such as architectural biofilm organization, physico274 chemical interactions between biofilm and substrate, and the control of gene expression. 275 Investigation of these processes will require multidisciplinary approaches aimed at (1) 276 identifying the genes/proteins involved in biofilm formation, (2) deciphering the architecture 
277 of biofilms, and (3) characterizing at the physico-chemical level the interactions between

278 biofilm components (cells and extracellular matrix) with hydrophobic substrates. So far, 279 investigations on biofilms on HOCs have been conducted on different strains growing on 280 various substrates in diverse experimental setups. It was therefore not possible to correlate 281 these results in order to draw a picture of the functioning of these biofilms. The study of 282 additional?? model bacteria, chosen for their ability to form readily and reproducibly biofilms 283 on HOCs, their genetic amenability, and the availability of their genome sequence would 284 ensure the complementarity of the data obtained from multidisciplinary approaches. In 285 addition to studies examining model single species biofilms on HOCs, investigations of the 286 activities and biodiversity of multispecies biofilms isolated from samples collected from 287 various environments are critical to gain full understanding of the ecological significance of 288 these biofilms.

289 Due to their wide distribution in the environment, their recalcitrance, and their deleterious 290 effect on human health, hydrocarbons have been the main molecules used in studies of 291 biofilm formation on HOCs. However, other classes of HOCs should also be taken into 292 consideration. In the natural environment, lipids represent a very abundant class of HOCs. For 293 example in sea water they represent up to about $15 \%$ of the organic carbon and its 294 biodegradation is relevant to the global carbon cycle (Lee et al., 2004). Consistent with this, 295 some bacterial strains isolated for their hydrocarbon-degrading capacities also form biofilms 296 on a larger panel of HOCs. This suggests that HOCs-degrading bacteria may have the ability 297 to form oleolytic biofilms that can cope with several types of hydrophobic organic carbon 298 they may encounter in the environment by adapting their physiology according to the 299 chemical nature of the HOC. 


\section{$302 \quad$ Figure 1}

303 M. hydrocarbonoclasticus SP17 biofilms growing on alkanes.

304 A and B, confocal scanning laser microscopy images of a biofilm covered $n$-hexadecane 305 droplet. Hydrophobic regions including bacteria as well as hydrocarbon were stained with red 306 Nile (red signal), glycoconjugates were stained with PSA lectin (green signal). In A, the data 307 are presented as an isosurface projection where the two signals have been split. In $\mathrm{B}$, the 308 dataset is presented as an XYZ projection. The two signals were not separated, colocalized 309 signals of the green and red channel appear in yellow indicating the colocalization of Nile red

310 and lectin stain. Images courtesy by Pierre-Jo Vaysse and Thomas R. Neu (Helmholtz Centre 311 for Environmental Research - UFZ, Magdeburg, Germany). C, picture of $M$. 312 hydrocarbonoclasticus SP17 biofilm growing at the surface of solid eicosane. 

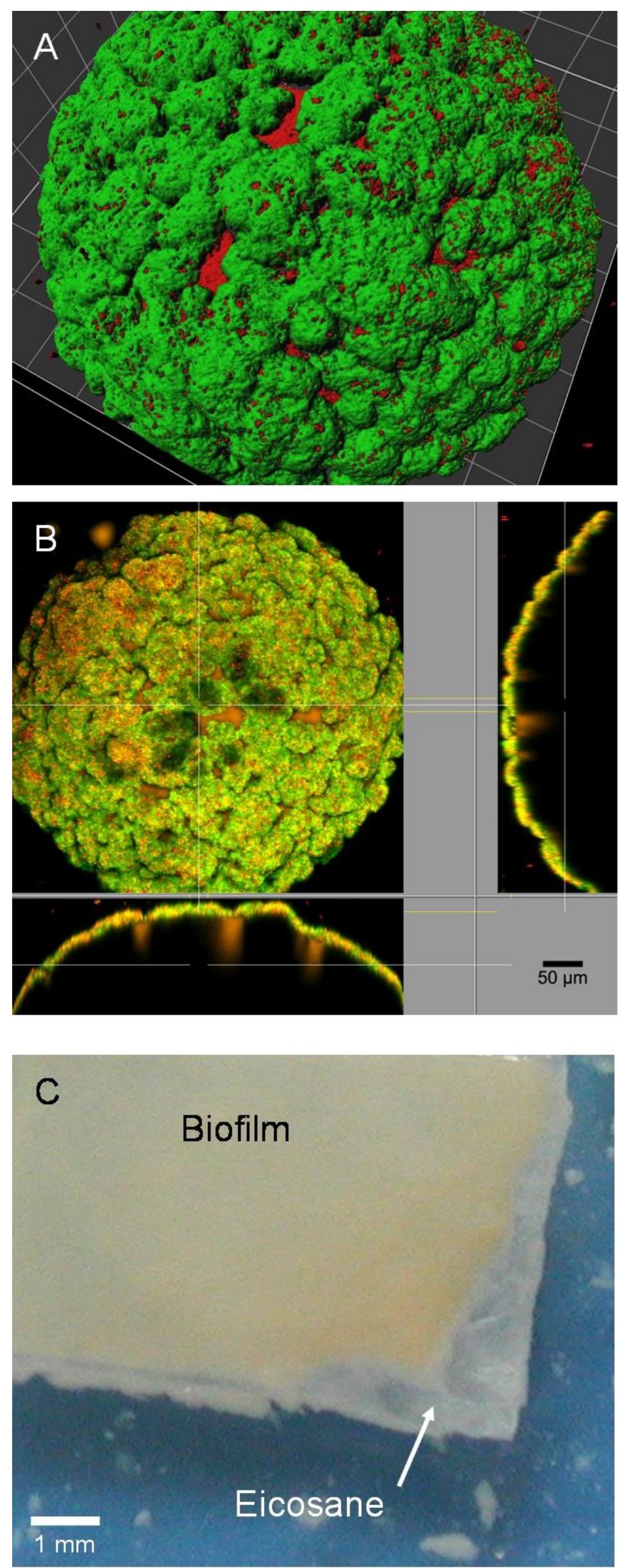


\section{References}

Abbasnezhad H, Gray M, Foght JM (2011) Influence of adhesion on aerobic biodegradation and bioremediation of liquid hydrocarbons. App. Microbiol. Biotechnol. 92:653-675

Al-Tahhan RA, Sandrin TR, Bodour AA, Maier RM (2000) Rhamnolipid-induced removal of lipopolysaccharide from Pseudomonas aeruginosa: Effect on cell surface properties and interaction with hydrophobic substrates. Appl. Environ. Microbiol. 66:3262-3268

Baelum J, Borglin S, Chakraborty R, Fortney JL, Lamendella R, Mason OU, Auer M, Zemla M, Bill M, Conrad ME, Malfatti SA, Tringe SG, Holman HY, Hazen TC, Jansson JK (2012) Deep-sea bacteria enriched by oil and dispersant from the Deepwater Horizon spill. Environ. Microbiol. 14:2405-2416

Baldi F, Ivoševic N, Minacci A, Pepi M, Fani R, Svetličic V, Žutic V (1999) Adhesion of Acinetobacter venetianus to diesel fuel droplets studied with in situ electrochemical and molecular probes. Appl. Environ. Microbiol. 65:2041-2048

Baldi F, Pepi M, Capone A, della Giovampaola C, Milanesi C, Fani R, Focarelli R 2003 Envelope glycosylation determined by lectins in microscopy sections of Acinetobacter Venetianus induced by diesel fuel. Res. Microbiol. 154:417-424

Barkay T, Navon-Venezia S, Ron EZ, RosenbergE (1999) Enhancement of solubilization and biodegradation of polyaromatic hydrocarbons by the bioemulsifier alasan. App. Environ. Microbiol. 65:2697-2702.

Bastiaens L, Springael D, Wattiau P, Harms H, deWachter R, Verachtert H, Diels L (2000) Isolation of adherent polycyclic aromatic hydrocarbon (PAH)-degrading bacteria using PAH-sorbing carriers. Appl. Environ. Microbiol. 66:1834-1843

Bendinger B, Rijnaarts HHM, Altendorf K, Zehnder AJB (1993) Physicochemical cell surface and adhesive properties of coryneform bacteria related to the presence and chain length of mycolic acids. Appl. Environ. Microbiol. 59:3973-3977

Bihari Z, Pettko-Szandtner A, Csanadi G, Balazs M, Bartos P, Kesseru P, Kiss I, Mecs I (2007) Isolation and characterization of a novel $n$-alkane-degrading strain, Acinetobacter haemolyticus AR-46. Zeitschrift fur Naturforschung - Section C J. Biosci. 62:285-295

Bouchez-Naïtali M, Blanchet D, Bardin V, Vandecasteele JP (2001) Evidence for interfacial uptake in hexadecane degradation by Rhodococcus equi: The importance of cell flocculation. Microbiology 147:2537-2543

Bouchez-Naïtali M, Rakatozafy H, Leveau JY, Marchal R, Vandecasteele JP (1999) Diversity of bacterial strains degrading hexadecane in relation to the mode of substrate uptake. $\mathrm{J}$. Appl. Microbiol. 86:421-428 
Bouchez M, Blanchet D, Vandecasteele JP (1997) An interfacial uptake mechanism for the degradation of pyrene by a Rhodococcus strain. Microbiology 143:1087-1093

Calvillo YM, Alexander M (1996) Mechanism of microbial utilization of biphenyl sorbed to polyacrylic beads. Appl. Microbiol. Biotechnol. 45:383-390

Deppe U, Richnow HH, Michaelis W, Antranikian G (2005) Degradation of crude oil by an arctic microbial consortium. Extremophiles 9:461-470

Efroymson RA, Alexander M (1991) Biodegradation by an Arthrobacter species of hydrocarbons partitioned into an organic solvent. Appl. Environ. Microbiol. 57:14411447

Ennouri H, d'Abzac P, Hakil F, Branchu P, Naïtali M, Lomenech AM, Oueslati R, Desbrières J, Sivadon P, Grimaud R (2017) The extracellular matrix of the oleolytic biofilm of Marinobacter hydrocarbonoclasticus comprises cytoplasmic proteins and T2SS effectors that promote growth on hydrocarbons and lipids. Environ. Microbiol. 19:159-73

Eriksson M, Dalhammar G, Mohn WW (2002) Bacterial growth and biofilm production on pyrene. FEMS Microbiol. Ecol. 40:21-27

Flemming HC, Wingender J (2010) The biofilm matrix. Nature Rev. Microbiol. 8:623-633

Golyshin PN, Chernikova TN, Abraham WR, Lunsdorf H, Timmis KN, Yakimov MM (2002) Oleiphilaceae fam. nov., to include Oleiphilus messinensis gen. nov., sp. nov., a novel marine bacterium that obligately utilizes hydrocarbons. Int. J. Syst. Evol. Microbiol. 52:901-911.

Guha S, Jaffé PR (1996) Biodegradation kinetics of phenanthrene partitioned into the micellar phase of nonionic surfactants. Environ. Sci. Technol. 30:605-611

Hardegger M, Koch AK, Ochsner UA, Fiechter A, Reiser J (1994) Cloning and Heterologous Expression of a gene encoding an alkane-induced extracellular protein involved in alkane assimilation from Pseudomonas aeruginosa. Appl. Environ. Microbiol. 60:3679-3687

Harms H, Smith KEC, Wick LY (2010) Microorganism-hydrophobic compound interactions. In Handbook of Hydrocarbon and Lipid Microbiology, ed Timmis KN, 1479-1490. Springer Berlin Heidelberg

Harms H, Zehnder AJB (1995) Bioavailability of sorbed 3-chlorodibenzofuran. Appl. Environ. Microbiol. 61:27-33

Hazen TC, Eric A, Dubinsky EA, DeSantis TZ, Andersen GL, Piceno YM, Singh N, Jansson JK, Probst A, Borglin SE, Fortney JL, Stringfellow WT, Bill M, Conrad ME, Tom LM, Chavarria KL, Alusi TR, Lamendella R, Joyner DC, Spier C, Baelum J, Auer M, Zemla ML, Chakraborty R, Sonnenthal EL, D'haeseleer P, Holman HYN, Osman S, Lu Z, Van Nostrand JD, Deng Y, Zhou J, Mason OU (2010) Deep-sea oil plume enriches indigenous oil-degrading bacteria. Science 330:204-208 
Hermansson M (1999) The DLVO theory in microbial adhesion. Colloids Surf. B: Biointerfaces 14:105-119

Holden PA, LaMontagne MG, Bruce AK, Miller WG, Lindow SE (2002) Assessing the role of Pseudomonas aeruginosa surface-active gene expression in hexadecane biodegradation in sand. Appl. Environ. Microbiol. 68:2509-2518

Joannis-Cassan C, Delia ML, Riba JP (2005) Limitation phenomena induced by biofilm formation during hydrocarbon biodegradation. J. Chem. Technol. Biotechnol. 80:99106

Johnsen AR, Karlson U (2004) Evaluation of bacterial strategies to promote the bioavailability of polycyclic aromatic hydrocarbons. Appl. Microbiol. Biotechnol. 63:452-459.

Katsutoshi H, Ishikawa M, Yamada M, Higuchi A, Ishikawa Y, Hironori E (2011) Production of peritrichate bacterionanofibers and their proteinaceous components by Acinetobacter sp. Tol 5 cells affected by growth substrates. J. Biosci. Bioeng. 111:3136

Kennedy RS, Finnerty WR, Sudarsanan K, Young RA (1975) Microbial assimilation of hydrocarbons. I. The fine structure of a hydrocarbon oxidizing Acinetobacter sp. Arch. Microbiol. 102:75-83

Kenichi H, Nakahara T, Minoda Y, Yamada K (1977) Formation of protein-like activator for n-alkane oxidation and its properties. Agric. Biol. Chem. 41:445-450

Klein B, Grossi V, Bouriat P, Goulas P, Grimaud R (2008) Cytoplasmic wax ester accumulation during biofilm-driven substrate assimilation at the alkane-water interface by Marinobacter hydrocarbonoclasticus SP17. Res. Microbiol. 159:137-144

Lanfranconi MP, Studdert CA, Alvarez HM (2003) A strain isolated from gas oilcontaminated soil displays chemotaxis towards gas oil and hexadecane. Environ. Microbiol. 5:1002-1008

Lee C, Wakeham S, Arnosti C (2004) Particulate organic matter in the sea: he composition conundrum. AMBIO. 33:565-575

Macedo AJ, Kuhlicke U, Neu TR, Timmis KN, Abraham WR (2005) Three stages of a biofilm community developing at the liquid-liquid interface between polychlorinated biphenyls and water. Appl. Environ. Microbiol. 71:7301-7309

Mounier J, Camus A, Mitteau I, Vaysse PJ, Goulas P, Grimaud R, Sivadon P (2014) The marine bacterium Marinobacter hydrocarbonoclasticus SP17 degrades a wide range of lipids and hydrocarbons through the formation of oleolytic biofilms with distinct gene expression profiles. FEMS Microbiol. Ecol. 90:816-831 
Mulder H, Breure AM, Van Honschooten D, Grotenhuis JTC, Van Andel JG, Rulkens WH (1998) Effect of biofilm formation by Pseudomonas 8909n on the bioavailability of solid naphthalene. Appl. Microbiol. Biotechnol. 50:277-283

Pandey G, Jain RK (2002) Bacterial chemotaxis toward environmental pollutants: Role in bioremediation. Appl. Environ. Microbiol. 68:5789-5795

Parche S, Geißdöfer W, Hillen W (1997) Identification and characterization of xcpR encoding a subunit of the general secretory pathway necessary for dodecane degradation in Acinetobacter calcoaceticus ADP1. J. Bacteriol. 179:4631-4634

Perfumo A, Smyth TJP, Marchant R, Banat IM (2010) Production and roles of biosurfactants and bioemulsifiers in accessing hydrophobic substrates. In Handbook of Hydrocarbon and Lipid Microbiology, ed Timmis KN, 1501-1512. Springer Berlin Heidelberg

Rodrigues AC, Brito AG, Wuertz S, Melo LF (2005) Fluorene and phenanthrene uptake by Pseudomonas putida ATCC 17514: Kinetics and physiological aspects. Biotechnol. and Bioeng. 90:281-289

Ron EZ, Rosenberg E (2010) Protein emulsifiers. In Handbook of Hydrocarbon and Lipid Microbiology, ed Timmis KN, 3031-3035. Springer Berlin Heidelberg.

Ron EZ, Rosenberg E, (2002) Biosurfactants and oil bioremediation. Curr. Opin. Biotechnol. $13: 249-252$

Rosenberg M, Bayer EA, Delarea J, Rosenberg E (1982) Role of thin fimbriae in adherence and growth of Acinetobacter calcoaceticus RAG-1 on hexadecane. Appl. Environ. Microbiol. 44:929-937

Rosenberg M, Rosenberg E (1981) Role of adherence in growth of Acinetobacter calcoaceticus RAG-1 on hexadecane. J. Bacteriol. 148:51-57.

Stach JEM, Burns RG (2002) Enrichment versus biofilm culture: A functional and phylogenetic comparison of polycyclic aromatic hydrocarbon-degrading microbial communities. Environ. Microbiol. 4:169-182

Stewart PS, Franklin MJ (2008) Physiological heterogeneity in biofilms. Nat. Rev. Microbiol. 6:199-210

Vaysse PJ, Prat L, Mangenot M, Cruveiller S, Goulas P, Grimaud R, (2009) Proteomic analysis of Marinobacter hydrocarbonoclasticus SP17 biofilm formation at the alkane-water interface reveals novel proteins and cellular processes involved in hexadecane assimilation. Res. Microbiol. 160:829-837

Vaysse PJ, Sivadon P, Goulas P, Grimaud R (2010) Cells dispersed from Marinobacter hydrocarbonoclasticus SP17 biofilm exhibit a specific protein profile associated with a higher ability to reinitiate biofilm development at the hexadecane-water interface. Environ. Microbiol. 13:737-746 
Webb JS, Givskov M, Kjelleberg S (2003) Bacterial biofilms: Prokaryotic adventures in multicellularity. Curr. Opin. Microbiol. 6:578-585

Whyte LG, Slagman SJ, Pietrantonio F, Bourbonnière L, Koval SF, Lawrence JR, Inniss WE, Greer CW (1999) Physiological adaptations involved in alkane assimilation at a low temperature by Rhodococcus sp. strain Q15. Appl. Environ. Microbiol. 65:2961-2968

Wick LY, De Munain AR, Springael D, Harms H (2002) Responses of Mycobacterium sp. LB501T to the low bioavailability of solid anthracene. Appl. Microbiol. Biotechnol. 58:378-385

Wick LY, Pasche N, Bernasconi SM, Pelz O, Harms H (2003) Characterization of multiplesubstrate utilization by anthracene-degrading Mycobacterium frederiksbergense LB501T. Appl. Environ. Microbiol. 69:6133-6142

Willison JC (2004) Isolation and characterization of a novel sphingomonad capable of growth with chrysene as sole carbon and energy source. FEMS Microbiol. Lett. 241:143-150

Wolfaardt GM, Lawrence JR, Robarts RD, Caldwell DE (1995) Bioaccumulation of the herbicide diclofop in extracellular polymers and its utilization by a biofilm community during starvation. Appl. Environ. Microbiol. 61:152-158

Zilber Kirschner I, Rosenberg E, Gutnick D (1980) Incorporation of ${ }^{32} \mathrm{P}$ and growth of pseudomonad UP-2 on $n$-tetracosane. Appl. Environ. Microbiol. 40:1086-1093 